\title{
DETERMINATION OF ANAEROBIC CAPACITY OF YOUNG GYMNASTS
}

\author{
Tatyana Dzimbova, Aleksander Markov \\ South-West University "Neofit Rilski", Blagoevgrad, Bulgaria
}

\begin{abstract}
Gymnastics requires explosive sprinting, jumping, pushing and pulling skills, together with balance and artistry. On the vault, balance beam and floor, explosive leg power plays an important role in connecting elements and acrobatic series. The aim of the study is to estimate anaerobic power by two tests: Wingate anaerobic test and Sargent jump test.

The study includes 14 gymnasts $(14.47 \pm 6.68$ years, $149.90 \pm 14.36 \mathrm{~cm}, 44.38 \pm 12.61 \mathrm{~kg})$. Their antropometric data and body compositions were measured using body mass analyser IOI353. The study was approved by University Research Ethics Committee. Wingate anaerobic test involved $30 \mathrm{sec}$ of pedaling as fast as possible on a Monark bicycle ergometer against an external force. The amount of workload in the Wingate test was $0.075 \mathrm{~kg}$ per $\mathrm{kg}$ body weight of the subject. To measure the blood lactate concentration with biochemical analyzer (Biosen-C line, EKF Diagnostic), blood samples were collected at rest (before warm-up) and at $1^{1^{s t}}, 3^{\text {rd }}$ and $5^{\text {th }}$ minutes after the end of the Wingate test.

Results from both anaerobic tests showed a very high degree of correlation (Pearson $r=0.94, p<0.0001$ ). Children are more aerobic than adults but the results showed that after the appropriate training they could develop their anaerobic capacity. Gymnasts age 8-12 have relative peak power lower than older gymnast but their fatigue indexes (45 to $54 \%$ older and 21 to $36 \%$ younger) were higher which proves again that children have faster oxygen uptake kinetics during high intensity exercise than do adults and a 30-s test with children is likely to include a significant contribution from aerobic metabolism, so their blood lactate concentration is significantly lower.

Determination and controlling of the anaerobic capacity development in young gymnasts could be successfully performed by these two tests.
\end{abstract}

Key words: Wingate test, gymnastics, anaerobic capacity

\section{INTRODUCTION}

Gymnastics is a sport that involves exercises that require balance, strength, flexibility, agility, coordination and endurance. The movements associated with gymnastics contribute to the development of muscle groups on the hands, legs, shoulders, back, chest and abdomen. The artistic gymnastics is an Olympic sport. The apparatuses used by men and women have differences, as there are apparatuses that are only for men or women. Female's artistic gymnastics includes 4 apparatuses: vault, uneven bars, balance beam, and floor. Men's artistic gymnastics includes 6 apparatuses: floor, pommel horse, rings, vault, parallel bars, and horizontal bar.

The characteristics of athletes in different sports disciplines are the result of selection and specific training (Cuk et al., 2007). Gymnastics require explosive sprinting, jumping, pushing and pulling skills together with balance and artistic. On vault, balance beam and floor the explosive force of the legs plays an important role in the connecting elements and the acrobatic series. Jumping is one of the most important movements in floor combinations and vaults and is developed by gymnasts at an early age as part of daily training (Marina, Torrado, 2013).

Children are more often engaged in very intense, short-duration activities than in less intensive activities of longer duration (Bailey et al., 1995). Moreover, most daily tasks, games, or youth sports primarily require short bursts of intense exercise (Rowland, 2005). Anaerobic performance therefore seems to be an important physiologic factor of the child's functional ability. As children are less anaerobic than adults are, it is questionable how critical anaerobic capacity is to their well-being. Athletic considerations seem to be more important for anaerobic testing in children (Bongers et al., 2015).

Some important peculiarities between children and adults and their responses to physical exercise indicate that children are not mature enough. In many sports, lack of maturity works to the detriment of children and they cannot meet the norms of older and younger adults. The biggest differenc- 
es are related to anaerobic energy generation, and the children have serious functional disadvantages compared to adults when performing heavy (supermaximal) loads lasting from 10 to $60 \mathrm{~s}$.

\section{Aim}

The aim of the present study is to determine the anaerobic power of lower limbs by two methods Wingate test and Sargent test and to find some dependencies between power and age, muscle mass, blood lactate concentration.

\section{METHODS}

\section{Subjects}

The study was conducted at the end of January 2019. It was approved by University Research Ethics Committee of South-West University, Blagoevgrad. Before being included in the study gymnasts and their parents learn about the methods that will be used, as well as the objectives of this study. Parents sign a declaration of informed consent. In the study participated 14 gymnasts from GC Pirin 2011 - Blagoevgrad (age - $14.47 \pm 6.68$ years, height $-149.90 \pm 14.36 \mathrm{~cm}$, weight $-44.38 \pm 12.61 \mathrm{~kg}$ ). The subjects attend the Center for Functional Studies in Sports and Kinesitherapy - SWU "Neofit Rilski", Blagoevgrad, where all the researches were carried out. The anthropometric measurements were performed on the first venue in the center, and on the second venue they performed the tests of anaerobic capacity.

\section{Anthropometric measurements}

Prior to the study, participants were asked to refrain from physical exercise, food, and fluid intake. Height and weight was measured as well as a body composition with a bioelectric impedance analyzer Ioi 353.

\section{Wingate test}

The test is carried out with the Monarch $828 \mathrm{E}$ mechanically-braked cycle ergometer. Following a five-minute warm-up, the athlete begins to pedal as fast as possible without any resistance. Within three seconds, a fixed resistance ( $7 \%$ of body weight) is applied to the flywheel and the athlete continues to pedal "all out" for the duration of 30 seconds. At the end of the test, the maximum power (Peak Power) is set for 5 seconds. This is the maximum power the person can develop during the first 5 seconds. The system also allows determining the average power for 30 seconds. The relative average power is determined by dividing the average power by the subject's weight.

\section{Determination of blood glucose and lactate}

Measurement is performed with BIOSEN C Line biochemical analyzer of the German company EKF Diagnostic. The determination of glucose and lactate in the blood is based on electrochemical measurement with a chip sensor.

\section{Sargent test}

The purpose of this test is to determine the explosive force of the muscles of the lower limbs. To perform the test, a wall, a centimeter strip of 1 meter long, a chalk and an assistant are needed. The subject put chalk on the tip of his fingers. He stands sideways to the wall with the two soles firmly on the ground, stretches one hand at a maximum and marks the wall reached with his fingers (M1). From a place he jumps to the maximum height and again marks with chalk-coated fingers (M2). The difference M2-M1 was determined. The test is conducted three times, taking the best achievement.

\section{Data analysis}

GraphPad Prism (Ver 3.0) was used to process and analyze the data. The mean values, standard deviations and coefficients of variation of all variables are calculated by descriptive statistics. Experimental data are presented in two ways: - as mean \pm SD; and - as individual values for each person under study. For statistical analysis of the results (Mann Whitney test), the Graph Pad Prism statistical software was used to determine the Pearson's correlation coefficient and to generate graphs.

\section{RESULTS}

The study participants are divided into two groups depending on age: 8 are in the younger age group (8-12 years) (Table 1$)$ and 6 in the older group (1322 years) (Table 2 ). 
Table 1. Anthropometric data of the group of subjects aged 8-12 years.

\begin{tabular}{|c|c|c|c|c|c|c|c|c|}
\hline ID & Age, & Height, cm & Weight, & MBF, & LBM, & SLM, & BMI, $\mathrm{kg} / \mathrm{m}^{2}$ & Fatness, \\
\hline G2 & 8.0 & 128.0 & 27.4 & 1.9 & 25.5 & 23.9 & 16.7 & -23.9 \\
\hline G16 & 8.0 & 127.0 & 25.4 & 1.2 & 24.2 & 22.7 & 15.7 & -28.5 \\
\hline G4 & 10.0 & 143.0 & 40.2 & 4.6 & 35.6 & 33.2 & \begin{tabular}{|l|l|}
19.7 \\
\end{tabular} & -10.7 \\
\hline G5 & 10.0 & 143.0 & 36.2 & 3.2 & 33.0 & 30.9 & 17.7 & -19.6 \\
\hline G11 & 10.0 & 128.0 & 25.7 & 1.4 & 24.3 & 22.8 & 15.7 & -28.6 \\
\hline G22 & 10.0 & 153.0 & 44.6 & 8.3 & 36.3 & 33.7 & 19.1 & -13.4 \\
\hline G3 & 12.0 & 155.0 & 50.2 & 7.9 & 42.3 & 39.4 & 20.9 & -5.1 \\
\hline G9 & 12.0 & 149.0 & 40.5 & 6.9 & 33.6 & 31.2 & 18.2 & -17.0 \\
\hline Mean & \begin{tabular}{|l}
10.0 \\
\end{tabular} & 140.8 & 36.3 & 4.4 & 31.9 & 29.7 & 18.0 & -18.4 \\
\hline \pm SD & 1.5 & 11.6 & 9.3 & 2.9 & 6.6 & 6.1 & 1.9 & 8.5 \\
\hline
\end{tabular}

$M B F$ - mass of body fat, LBM - lean body mass, SLM - soft lean mass, BMI - body mass index

Table 2. Anthropometric data of the group of subjects aged 13-22 years.

\begin{tabular}{|c|l|l|l|l|l|l|l|l|}
\hline ID & Age, years & Height, $\mathbf{c m}$ & Weight, kg & MBF, kg & LBM, kg & SLM, kg & BMI, kg/m & Fatness, $\%$ \\
\hline G13 & 13.0 & 158.0 & 46.7 & 5.5 & 41.2 & 38.5 & 18.7 & -14.9 \\
\hline G14 & 14.0 & 155.0 & 48.1 & 10.5 & 37.6 & 34.8 & 20.0 & -9.1 \\
\hline G1 & 18.0 & 161.0 & 55.0 & 8.7 & 46.3 & 43.1 & 21.2 & -3.5 \\
\hline G24 & 18.0 & 170.0 & 56.0 & 7.0 & 49.0 & 45.7 & 19.4 & -11.9 \\
\hline G23 & 19.0 & 159.0 & 61.6 & 17.7 & 43.9 & 40.4 & 24.4 & 10.8 \\
\hline G21 & 22.0 & 169.0 & 63.7 & 10.8 & 52.9 & 49.2 & 22.3 & 1.4 \\
\hline Mean & 17.3 & 161.0 & 51.5 & 7.9 & 43.5 & 40.5 & 19.8 & -9.9 \\
\hline \pm SD & 3.3 & 6.5 & 4.7 & 2.2 & 5.1 & 4.8 & 1.1 & 4.9 \\
\hline
\end{tabular}

MBF - mass of body fat, LBM - lean body mass, SLM - soft lean mass, BMI - body mass index

After the Wingate test the results were summarized Lactate concentration at 1, 3 and 5 minutes after the in Table 3. There were correlations between the mu- test differed statistically from pretest concentration. scle mass and peak, minimum and average power There was a statistically significant difference betdetermined by Wingate test (Figure 1). This depen- ween the lactic acid concentration at 5 minutes after dence was expected, as the power depends directly the Wingate test of older subjects and the younger on the amount of muscle mass.

(Mann Whitney test, Figure 2).

Table 3. Summary data for Wingate test subjects: maximum, minimum, average and relative average power, and anaerobic fatigue.

\begin{tabular}{|l|l|l|l|l|l|}
\hline ID & \multicolumn{1}{|c|}{$\mathbf{P P}(\mathbf{W})$} & \multicolumn{1}{|c|}{$\mathbf{M P}(\mathbf{W})$} & \multicolumn{1}{c|}{$\mathbf{A P}(\mathbf{W})$} & \multicolumn{1}{c|}{$\mathbf{R A P}(\mathbf{W} / \mathbf{k g})$} & \multicolumn{1}{c|}{$\mathbf{A F}$ \% } \\
\hline G1 & 465.20 & 252.22 & 354.91 & 6.45 & 45.78 \\
\hline G2 & 116.26 & 73.78 & 97.03 & 3.54 & 36.54 \\
\hline G3 & 247.01 & 184.87 & 229.25 & 4.57 & 25.16 \\
\hline G4 & 217.95 & 159.10 & 189.68 & 4.72 & 27.00 \\
\hline G5 & 139.38 & 90.78 & 121.71 & 3.36 & 34.87 \\
\hline G9 & 181.40 & 123.52 & 151.45 & 3.74 & 31.91 \\
\hline G11 & 88.85 & 66.08 & 79.54 & 3.09 & 25.63 \\
\hline G13 & 322.81 & 169.28 & 244.37 & 5.23 & 47.56 \\
\hline G14 & 265.61 & 208.43 & 238.62 & 4.96 & 21.53 \\
\hline G16 & 80.38 & 45.86 & 59.65 & 2.35 & 42.95 \\
\hline G21 & 616.07 & 283.18 & 452.11 & 7.10 & 54.03 \\
\hline G22 & 210.34 & 128.17 & 169.67 & 3.80 & 39.07 \\
\hline G23 & 428.01 & 269.63 & 353.58 & 5.74 & 37.00 \\
\hline G24 & 391.92 & 256.22 & 332.56 & 5.94 & 34.62 \\
\hline
\end{tabular}

$P P$ - peak power, $M P$ - minimum power, $A P$ - average power, $R A P$ - relative average power 


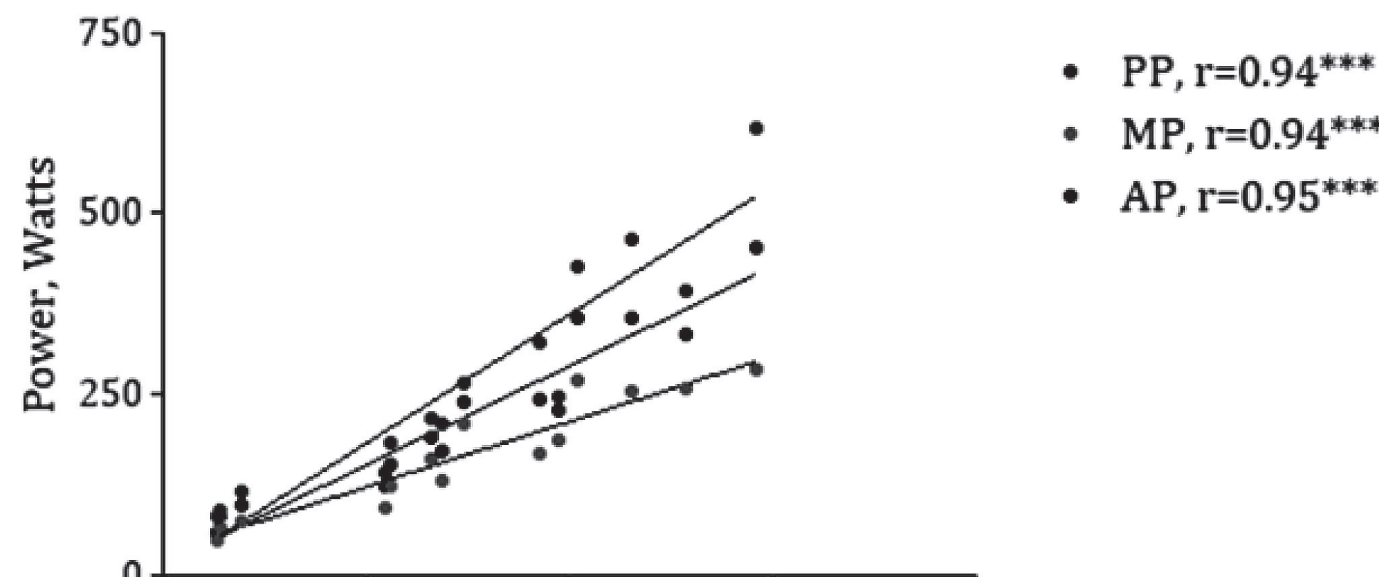

Figure 1. Correlations between muscle mass and maximum, minimum and average power $\left({ }^{* * *} p<0.0001\right)$.

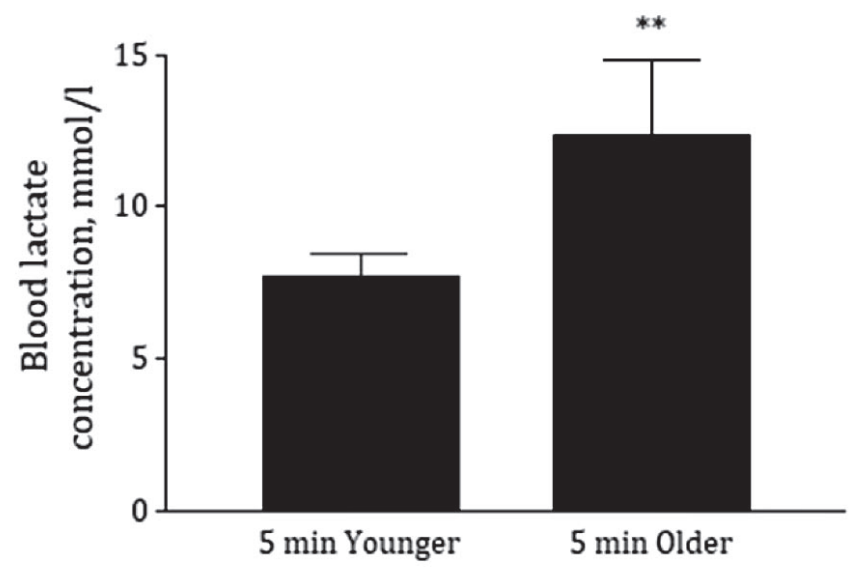

Figure 2. Lactate concentrations 5 minutes after a Wingate test in both groups of subjects.

The blood glucose concentration did not change The results of the Sargent test also correlated well before and after the Wingate test. with muscle mass (Figure 3).
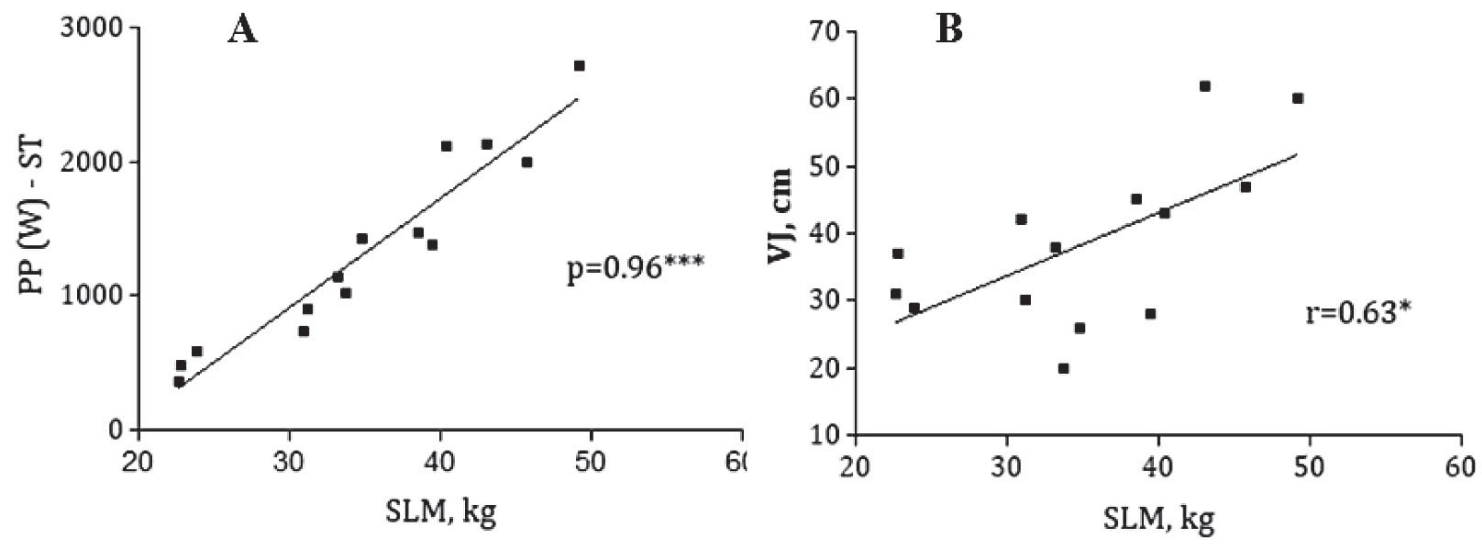

Figure 3. Correlations between muscle mass (A) and vertical jump height (B) and maximum power at the Sargent test.

Correlations were found between the Sargent Verti- cal Jump and Wingate Test data (Figure 4). 

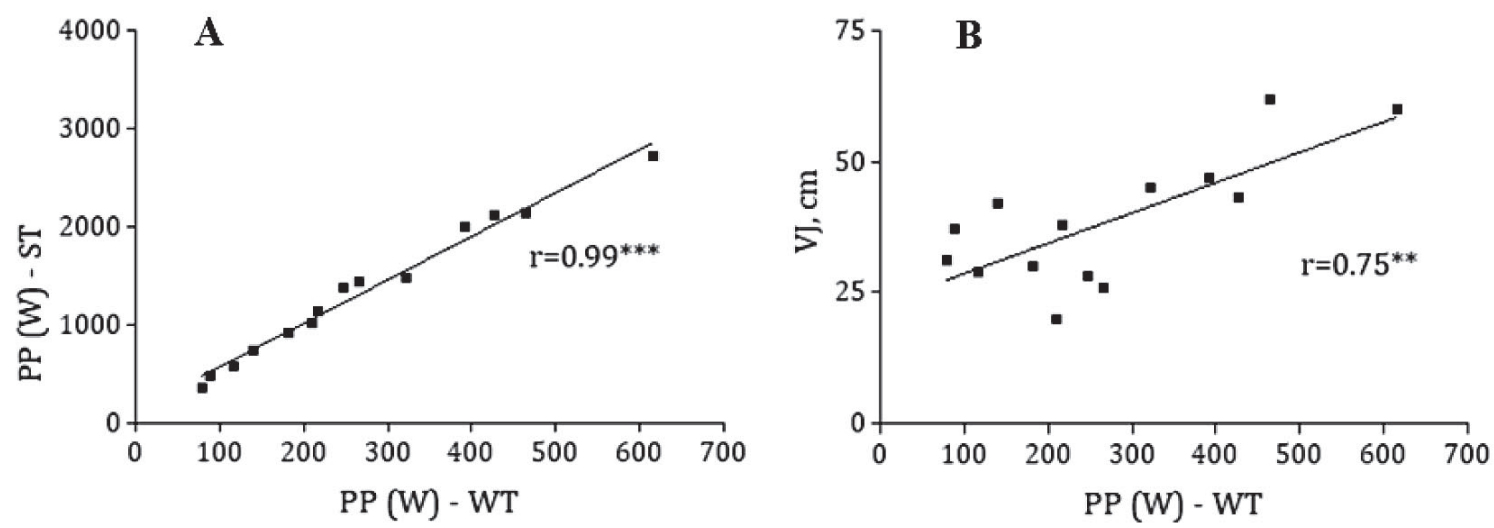

Figure 4. Dependencies between the Wingate Test and the Sargent Test-peak power in both tests (A); peak power of Wingate test and vertical jump height of Sargent test $(B)\left({ }^{* * *} p<0.0001,{ }^{* *} p=0.002\right)$.

\section{DISCUSSION}

In the first group the height was $140.8 \pm 11.6 \mathrm{~cm}$, weight $-36.3 \pm 9.3 \mathrm{~kg}$, BMI - $18.0 \pm 1.9$. The group is not homogeneous in terms of height and weight, as at this age subjects vary the most, but the BMI varies the least. In the second group height was 161.0 $\pm 6.5 \mathrm{~cm}$, weight $-51.5 \pm 4.7$ and BMI $-19.8 \pm 1.1$. Here again the same trend was observed - large differences in height and weight and small variations in BMI. Although gymnastics are generally slim and with a low body mass index, it was noticeable that it increases over the years and this is due to an increase in both the muscle mass as a result of the training and the percentage of body fat. The ratio of the weight of the gymnasts to the ideal weight in percent (fatness) was of negative value because they all weigh less than the so-called "ideal weight" for that height. This ratio was $-18.4 \pm 8.5 \%$ in the $8-12$ year age group and larger in the older group -9.9 $\pm 4.9 \%$, i.e. the increase was on average about $9 \%$. Despite this increase all gymnasts are distinguished by their low percentage of fat.

Currently, the Wingate anaerobic test (WT) in a laboratory setting on a cycle ergometer is accepted as golden standard for determining anaerobic performance. During the WT, the subject pedaled at maximal velocity against a constant breaking force for $30 \mathrm{~s}$. Performing of WT requires a combination of phospholytic, glycolytic, and aerobic power. Peak power (PP) reflects the ability of the leg muscles to produce short term mechanical power (peak phospholytic power), whereas average power (AP) best represents glycolytic power (local muscle endurance) of the legs. The WT has shown to be reliable and valid in children and adolescents with various chronic conditions. Some authors suggest shortening the Wingate test in children and running it instead of 30 seconds for 20 seconds (Chia et al., 1997), as the reason for this was that children work mainly in aerobic mode even at high intensive loads. This test determines the anaerobic capacity, which is extremely important in gymnastics. Most of the exercises required both technique and great explosive force. Children work mostly in aerobic mode, but under the training their body gradually adapts to the anaerobic regime. Usually, children started practicing gymnastics very early (about 3-4 years) when they started with general training and gradual inclusion of power elements. Even the smallest in the studied group had a gymnastics experience of about 4 years, time enough to bring about some adaptations. Adapted muscle, in addition to working in an anaerobic mode, began to accumulate larger amounts of glycogen to use at high intensities, and also tolerated higher lactate concentrations.

Average power and fatigue index (the difference between the maximum and minimum power of the Wingate test, as a percentage of the maximum power) indicate the capacity of the glycolytic system, especially in combination with the measurement of lactate concentration in the blood after loading (Lee, 1993). There is no correlation between the fatigue index and the muscle mass of the participants. The blood lactate concentrations differed between two groups. They were lower in the younger group. This was new evidence that the anaerobic capacity of 8-12 year old subjects still had not developed sufficiently, as the muscles did not tolerate large lactate concentrations. Along with the fatigue index, which was smaller in this group, it could be considered that group 8-12 relied on a large percentage of aerobic processes to provide energy at short intensive loads. Sargent test measured the vertical jump height. 
There are different norms for different subjects. Our subjects fall into different age groups, so the data analysis is consistent with different standards. When analyzing test results both the height of the vertical rebound and the maximum power were used. The maximum power is calculated using the Sayers equation because it includes the weight of the subject. A heavier person who jumps at the same height as the lighter should do more work because he has to move a larger mass. It is sometimes useful to convert the vertical height of the jump to units of power. The power cannot be calculated (Power $=$ Work $\div$ Time), since the time when the force acts on the body is unknown. Formulas have been developed to measure the power of the vertical jump measurements. The prediction equation (1) of Sayers et al. (1999) was used to calculate the peak power of the legs.

(1) Peak power $(\mathrm{W})=60.7 \times \mathrm{VJ}(\mathrm{cm})+45.3 \mathrm{x}$ $\operatorname{mass}(\mathrm{kg})-2055$,

where Peak power - maximum power, VJ - height of the vertical jump $(\mathrm{cm})$, mass - weight of the person under study $(\mathrm{kg})$.

To date, a prediction equation for children is not validated, so the Sayers equation, which includes the height of the jump and mass of the participant (Taylor et al., 2010) has been used. This equation, developed by jumps performed on a rebound platform, has a difference in adults of $2.7 \%$ with the power calculated by the platform (Sayers et al., 1999). Because the Sayers formula counted the weight of the participant, the maximum power correlated better with the muscle mass $(r=0.096, p<0.0001)$ than the vertical jump height $(\mathrm{r}=0.63, \mathrm{p}=0.01)$.

Wingate and Sargent tests were designed to assess the strength of the athlete's lower limbs. There was a strong correlation between the maximum power obtained by Wingate test $(\mathrm{r}=0.99, \mathrm{p}<0.001)$ and the maximum power calculated by the Sayers formula as well as the maximum power $(\mathrm{r}=0.75, \mathrm{p}$ $<0.02$ ) of Wingate test and the vertical jump height (Figure 4). The presence of such a strong correlation between the results of the two tests showed that they equally gave an idea of the anaerobic power of the subjects.

The Sargent test could be used to quickly assess the anaerobic capacity as a field test in the absence of suitable equipment for conducting the Wingate test.

\section{CONCLUSION}

The study made it possible to determine the anaerobic capacity of young gymnasts and to lay the foundations for tracking their development. Together with body composition, the data could be used to monitor the training process and the changes that occur in the subjects. These data could be used to initiate a longitudinal study with these individuals.

\section{REFERENCES}

Bailey, R. C., Olson, J., Pepper, S. L., Porszasz, J., Barstow, T. J., and Cooper, D. M. (1995). The level and tempo of children's physical activities: an observational study. Med Sci Sports Exerc, Vol. 27, No. 7, pp. 1033-1041.

Bongers, B. C., Werkman, M. S., Blokland, D., Eijsermans, M. J., van der Torre, P., Bartels, B., and Takken, T. (2015). Validity of the Pediatric Running-Based Anaerobic Sprint Test to Determine Anaerobic Performance in Healthy Children. Pediatric Exercise Science, Vol. 27, pp. 268-276.

Chia, M., Armstrong, N., and Childs, D. (1997). The Assessment of Childrens Anaerobic Performance Using Modifications of the Wingate Anaerobic Test. Pediatric Exercise Science, Vol. 9, pp. 80-89.

Cuk, I., Korencic, T., Tomazo-Ravnik, T., Pecek, M., Bucar, M., and Hraski, Z. (2007). Differencies in morphologic characteristics between top level gymnasts of year 1933 and 2000. Collegium Antropologicum, Vol. 31, pp. 613-619.

Lee, M. (1993). Coaching Children in Sport. London and New York: Routledge, Taylor\&Francis Group.

Marina, M., \& Torrado, P. (2013). Does gymnastics practice inprove vertical jump reliability from the age of 8 to 10 years? Journal of sport sciences, 31(11), 1176-1186.

Rowland, T. W. (2005). Short-burst activities and anaerobic fitness, in T. W. Rowland (Ed.), Children's exercise physiology. Human Kinetics, Champaign, USA, pp. 165-180.

Sayers, S. P., Harackiewicz, D. V., Harman, E. A., Frykman, P. N., and Rosenstein, M. T. (1999). Cross-validation of three jump power equations. Medicine and Science in Sports and Exercise, Vol. 31, pp. 572-577.

Taylor, M. J., Cohen, D., Voss, C., and Sandecock, G. R. (2010). Vertical jumping and leg power normative data for English school children aged 10-15 years. Journal of Sports Sciences, Vol. 28, pp. 867-872.

Corresponding autor:

Tatyana Dzimbova

South-West University "Neofit Rilski", Blagoevgrad, Bulgaria E-mail: tania_dzimbova@abv.bg 